\title{
Cortical Cataract Grade 4
}

National Cancer Institute

\section{Source}

National Cancer Institute. Cortical Cataract Grade 4. NCI Thesaurus. Code C135200.

A stage of cortical cataract characterized by greater than $90 \%$ of the intrapupillary space obscured by opacity. (Modified LOCS II) 